\title{
The Effects of Saltwater Intrusion to Flood Mitigation Project
}

\author{
Azinoor Azida Abu Bakar ${ }^{1, *}$, and Muhammad Khairudin Khali1 ${ }^{2}$, \\ ${ }^{1}$ Faculty of Civil Engineering, Universiti Teknologi MARA, Johor Branch, Pasir Gudang Campus, \\ Bandar Seri Alam, 81750 Masai, Johor, Malaysia. \\ ${ }^{2}$ Department of Irrigation and Drainage, Bangunan Dato' Muhamad Ibrahim Munsyi, Pusat \\ Pentadbiran Kota Iskandar, 79626 Nusajaya, Johor, Malaysia.
}

\begin{abstract}
The objective of this study is to determine the effects of saltwater intrusion to flood mitigation project located in the flood plains in the district of Muar, Johor. Based on the studies and designs carried out, one of the effective flood mitigation options identified is the Kampung Tanjung Olak bypass and Kampung Belemang bypass at the lower reaches of Sungai Muar. But, the construction of the Kampung Belemang and Tanjung Olak bypass, while speeding up flood discharges, may also increase saltwater intrusion during drought low flows. Establishing the dynamics of flooding, including replicating the existing situation and the performance with prospective flood mitigation interventions, is most effectively accomplished using computer-based modelling tools. The finding of this study shows that to overcome the problem, a barrage should be constructed at Sungai Muar to solve the saltwater intrusion and low yield problem of the river.
\end{abstract}

\section{Introduction}

Sg. Muar is being extracted for water supply to the States of Johor, Malacca and Negeri Sembilan. There have been reported incidences of saltwater intrusion during drought into the raw water intake at Panchor, $68 \mathrm{~km}$ upstream from Sg. Muar river mouth, indicating either that the station was not located sufficiently upstream to avoid the saltwater intrusion or the raw water extraction from Sg. Muar has increased over the years and caused the saltwater intrusion to move further upstream during drought when fresh water discharge moving downstream is very low.

The Sungai Muar river basin was affected by two major flood events in December 2006 and January 2007, which caused massive floods with devastating damages within the river basin. Based on the original studies and designs carried out and completed in 2011 [1] the Kg. Tg. Olak Bypass and the Kg. Belemang Bypass have been identified as one of the effective flood mitigation components that will reduce future flooding and consequential hazards within the Sg. Muar river basin. There is concern that construction of the Kg. Belemang and Tg. Olak Bypasses, while speeding up flood discharges, may also increase

* Corresponding author: khairudinkhalil@yahoo.co.uk 
saltwater intrusion during drought low flows since the 2 new bypasses will reduce the river distance between the river mouth to the raw water intake station at Panchor [1].

A variety of different measures are commonly used to control seawater intrusion and protect groundwater resources, although the target of most is to increase the flow of fresh groundwater and/or reduce the flow of saltwater. As such there are a number of methods with which to prevent saltwater contamination of groundwater, including subsurface barriers and artificial recharge [1]. Various reports reported [2, 3, 4], the insufficient yield of Sg. Muar to cater for the daily water supply demands of households in Johor, Malacca and Negeri Sembilan during drought season, which will be further aggravated if saltwater intrusion problem increases.

Contributory factors to flooding problems includes development in the catchment, leading to reductions in the time of concentration and increased flood discharges, human settlement and encroachment on the floodplain, the occurrence of high tides, exacerbated by low pressure and/or wind/wave set-up, siltation of waterways, due to erosion of soil from the catchment (exacerbated by poor sediment control practices at development sites), existence of rock outcrop (e.g. at Batu Liang) in the river channel and trees falling into Sg. Muar due to bank erosion [2, 5].

\section{Methodology}

\subsection{Site Area}

The project is situated at the lower reaches of the Sg. Muar basin, which is located in the north-western part of Johor State as shown in Fig. 1.

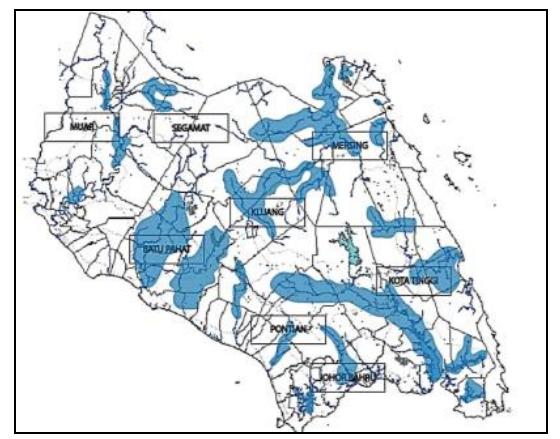

Fig. 1. Project location plan.

With a total catchment area of $6,595 \mathrm{~km}^{2}$, part of the Sg Muar catchment boundary is within the states of Negeri Sembilan and Pahang. Sg. Muar rises at an elevation of $350 \mathrm{~m}$ at Kg Lubok Kadam (District of Kuala Pilah, Negeri Sembilan) and flows in a predominantly easterly direction through Gemas before turning near Segamat to flow south and turning west to reach the Straits of Melaka at Muar. In its lower reaches, Sg Muar is characterised by numerous large meanders. The main channel of Sg Muar is about $310 \mathrm{~km}$ long and the average annual discharge at its estuary is about $140 \mathrm{~m}^{3} / \mathrm{s}$. The two main population centres within the river basin are Segamat (on Sg Segamat) and Muar at the Sg Muar river mouth. The total population of the river basin is made up of 250,000 at Segamat District $(2,825$ $\left.\mathrm{km}^{2}\right)$ and 450,000 at Muar District $\left(2,346 \mathrm{~km}^{2}\right)$ [5]. 


\subsection{Climate}

The study area experiences typical humid equatorial climate with high temperature and humidity all year round. The average monthly low temperature is $23^{\circ} \mathrm{C}-24^{\circ} \mathrm{C}$ and the high temperature is $31^{\circ} \mathrm{C}-33^{\circ} \mathrm{C}$. The highest air temperature usually occurs from April to May and the lowest is from December to January. The mean annual humidity is above $80 \%$. The annual rainfall in the project area ranges from $1,300 \mathrm{~mm}$ to $2,400 \mathrm{~mm}$. Heaviest rainfall is from the Northeast monsoon in November to December. From May to July, the Southwest monsoon brings moderate rainfall to the project area.

\subsection{Soil and Geological Characteristics}

The study area being within the lower reaches of Sg. Muar, is generally flat and low lying with ground level of RL 1 to $2.5 \mathrm{~m}$. Oil palms and fruit trees dominate the landscape, with mangroves along the riverbanks. The geological formation of the project area basically consists of Quaternary Alluvium, which consists of very soft marine and fluviatile clays about $20 \mathrm{~m}$ thick underlain by sands and silts. No bedrocks are encountered down to $60 \mathrm{~m}$ below ground level. Groundwater is at 0 to $3 \mathrm{~m}$ below ground level, and fluctuates with wet / dry seasons and tides. The very soft marine clays are expected to pose very serious stability and settlement problems for the proposed works both during and after construction. Sand lenses in between and below the soft clays can also cause serious piping and boiling conditions during and after construction of the works.

\subsection{Recent Flood Events}

The two major flood events in recent years affecting the Sg Muar River Basin occurred in December 2006 (with a 48 hour rainfall of over 300mm) and January 2007. The extreme rainfalls from $17^{\text {th }}-20^{\text {th }}$ December 2006 caused Sg. Muar and its tributaries to overflow their banks and resulted in massive and widespread floods which were remarkable in extent, duration and depth and with devastating damages. The January 2007 flood event was of a lesser magnitude, but was nevertheless significant enough to cause widespread damages and disruption [2].

The township of Gerisek, Panchor, Pagoh, Kundang Ulu, Lena and Bukit Kepong were badly affected by the Dec 2006 and Jan 2007 flooding when Sungai Muar and Sungai Segamat overtopped their banks and flooded a large extent of the low-lying populated areas. Some 25,000 people in the Sg Muar River Basin left their homes to seek shelter in relief centres. Lives were lost as were crops and livestock. Millions of Ringgit worth of damages was caused to infrastructure such as roads, utilities, as well as personal properties and belongings. In some cases, road and rail embankments were eroded by floodwater and have necessitated expensive and time consuming reconstruction works. Many roads including the PLUS Expressway around KM 152 were inundated and made impassable. Some $397 \mathrm{~km}^{2}$ of the $\mathrm{Sg}$. Muar river basin was inundated with floodwater during the Dec 2006 and Jan 2007 floods [11]. Based on previous studies [2, 6], the Dec 2006 and Jan 2007 floods have been assessed to be of average recurrence interval (ARI) of between 70 to 100 years. The estimated flood map of the Lower Muar River Basin for 100 year ARI is shown in Fig. 2. 


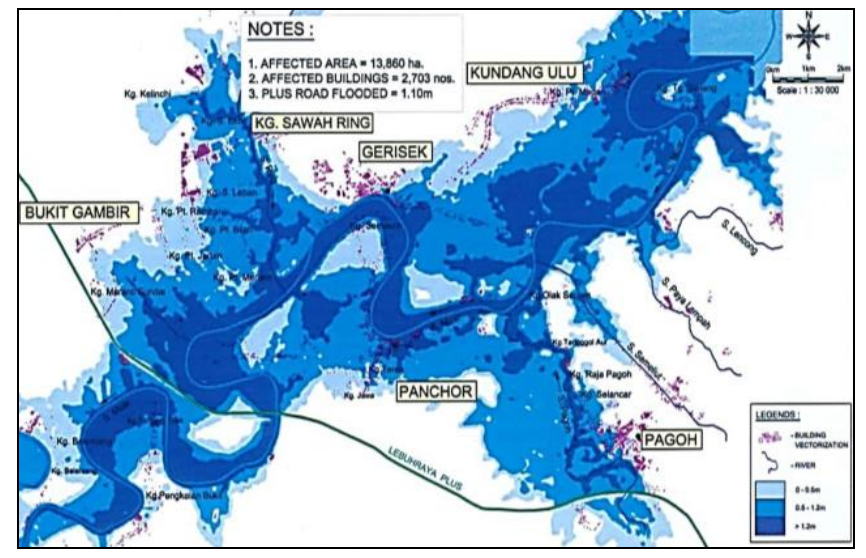

Fig. 2. 100 years ARI flood map for lower Sg Muar River basin.

\subsection{Data Collection and Model Calibration}

The Intensity-Duration-Frequency (IDF) analysis for six rainfall stations in Sg Muar basin was carried out by in 2003. Flood Frequency Analysis (FFA) for four water level gauging stations was conducted. A NAM hydrological model was established to simulate the rainfall runoff process for the entire Sg Muar basin.

The rainfall temporal patterns and Intensity-Duration-Frequency curves for six rainfall stations located within Sg Muar basin with different storm duration (15 min, $30 \mathrm{~min}, 60$ $\min , 120 \mathrm{~min}, 12$ hours, 24 hours and 72 hours) and return period (2, 5, 10, 20, 50 and 100 years) has been derived. These patterns were then used as the rainfall input in the hydrological model to produce the design flood.

The study area, which involves a total of $6,200 \mathrm{~km}^{2}$, was divided into $21 \mathrm{sub}-$ catchments, and was modelled using the NAM hydrological model. The model was calibrated with the flood data from two major flood events taking place in December 2006 and January 2007. In addition, the model was also calibrated based on Stream flow data obtained for the Segamat, Buloh Kasap and Bt. 57 stations.

\subsection{Flood Mitigation Proposal}

Although the events of Dec 2006 and Jan 2007 may have been unusual, it is intended to identify and carry out such mitigation works that may reduce future flooding and consequential hazards within the Sg Muar river basin. Based on the studies and designs carried out and completed in the year 2011 [1] one of the effective flood mitigation option identified are the $\mathrm{Kg}$. Tg. Olak Bypass and $\mathrm{Kg}$. Belemang Byass at the lower reaches of Sg Muar. The proposed Tg Olak and Kg Belemang Bypasses are located in the flood plains of Lower Muar at Tg Olak and Kg Belemang respectively in the district of Muar, Johor. The main function of these bypasses is to cut through 2 meanders to reduce the flow distance from $27 \mathrm{~km}$ to $6 \mathrm{~km}$ to effectively increase the hydraulic gradient and hasten the evacuation of flood waters to the sea thereby alleviating flooding and mitigating floods in the town of Gerisek, Panchor, Pagoh and Lenga for the 100 year ARI event.

Hydraulic profile of the river flood water level before and after the construction of the bypasses is shown in Fig. 3. It is to be noted that flooding along $\mathrm{Sg}$. Muar will still occur after completion of $\mathrm{Kg}$. Belemang and Tg. Olak Bypasses as these are just part of the whole of Sg. Muar flood mitigation works. 


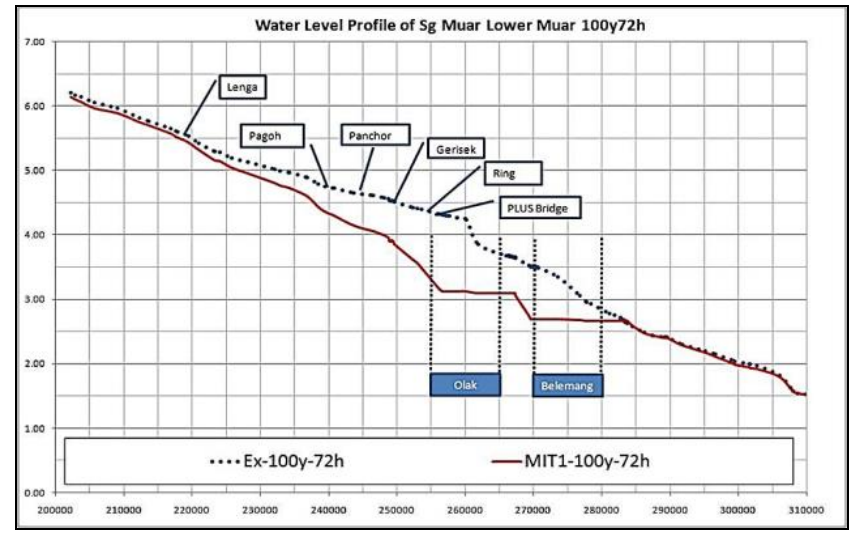

Fig. 3. Profile of water level at lower Muar with bypasses.

\section{Results and discussions}

\subsection{Sungai Muar Flood Mitigation}

The Intensity-Duration-Frequency (IDF) analysis for six rainfall stations in Sg Muar basin was carried out [3]. Flood Frequency Analysis (FFA) for four water level gauging stations was conducted. A NAM hydrological model was established to simulate the rainfall runoff process for the entire Sg Muar basin. Table 1 shows the 100 year ARI design runoff values obtained from Flood Frequency Analysis and Simulation from the Hydrological model at location upstream of Tg Olak.

Table 1. 100 year ARI design runoff estimation from Iktisas (2003) for specific gauge locations.

\begin{tabular}{|l|c|c|c|}
\hline \multicolumn{1}{|c|}{ Name } & Station No & $\begin{array}{c}\text { FFA 100 year ARI } \\
\left(\mathbf{m}^{\mathbf{3}} / \mathbf{s}\right)\end{array}$ & $\begin{array}{c}\text { Modelled 100 year } \\
\text { ARI }\left(\mathbf{m}^{\mathbf{3}} / \mathbf{s}\right)\end{array}$ \\
\hline Bt 57 & 2625412 & 660 & 1690 \\
\hline Buloh Kasap & 2527411 & 500 & 1500 \\
\hline Segamat & 2528414 & 1,350 & Not Available \\
\hline
\end{tabular}

The rainfall temporal patterns and Intensity-Duration-Frequency curves for six rainfall stations located within Sg Muar basin with different storm duration (15 min, $30 \mathrm{~min}, 60$ min, 120 min, 12 hours, 24 hours and 72 hours) and return period (2, 5, 10, 20, 50 and 100 years) has been derived. These patterns were then used as the rainfall input in the hydrological model to produce the design flood.

The study area, which involves a total of $6,200 \mathrm{~km}^{2}$, was divided into 21 subcatchments, and was modelled using the NAM hydrological model. The model was calibrated with the flood data from two major flood events taking place in December 2006 and January 2007. In addition, the model was also calibrated based on Stream flow data obtained for the Segamat, Buloh Kasap and Bt. 57 stations.

\subsection{Reviewed and Updated the Hydrological Procedures}

In the recent years, Malaysia has been experiencing extreme weather conditions of frequent floods. The utilisation of larger volume and longer record of available rainfall data ensured more accurate rainfall intensity estimation particularly at high return period [7]. It also 
provides the estimation of design rainstorm/rainfall intensity and IDF relationship at ungauged site such as Tg. Olak and others. A new Areal Reduction Factor (ARF) for catchment rainfall was developed in the study. Equation in the revised HP1 (2010) [7],

$$
i=\frac{\lambda \mathrm{T}^{\kappa}}{(d+\theta)^{\eta}}
$$

The derived parameters including $\lambda, \kappa, \theta$ and $\eta$ was generalised for the construction of ungauged IDF relationship where $\lambda$ is the mean number of peaks per year included in the partial duration series ; $\kappa$ is the important shape parameter ; $T$ is the return period ; $d$ is duration; and $\theta$ and $\eta$ are non-negative coefficients. IDF curves for a control point have been developed using HP1 [7].

The Town and Country Planning Department reviewed the Draf Rancangan Tempatan Daerah Muar in 2010 [8]. The review indicates that the increase in development area including Residential, Industrial, Trading and Services, and Institutions and Community Facilities is up to 4307.94 hectare. On the other hand, there is a decrease of 814.9 hectare of land in the Open Space and Recreation area. These imply that the impervious area within the catchment area has increased accordingly, which contribute to greater runoff during storm event

\subsection{Hydrological Modelling}

The hydrological modelling was carried out using DHI's NAM. NAM a parametric lumped hydrologic model that simulates the land phase of the hydrologic cycle. Meteorological inputs to the model are rainfall and potential evapotranspiration. Input rainfall data used in the hydrological modelling are rainfall records from JPS stations (various) and the design rainfall for various return periods and storm durations.

Rainfall-runoff outputs are catchment runoff (split into surface flow, interflow and groundwater or baseflow), groundwater levels and other information such as moisture content and groundwater recharge.

\subsection{Future IDF curves}

HP1 [7] allows IDF curves to be developed for an ungauged site, for example, at Tg. Olak $\left(102^{\circ} 40^{\prime} \mathrm{E}, 2^{\circ} 10^{\prime} \mathrm{N}\right)$, where no JPS hydrological stations are available. Derived parameters for Tg Olak are extracted using GIS and the corresponding values are shown in Fig. 4 and future IDF curve for Tg. Olak are shown in Fig. 5 and salt water intrusion as shown in Fig. 6 and Fig. 7 respectively. Based on the findings, the bypass will be designed for discharge of $2170 \mathrm{~m}^{3} / \mathrm{s}$ with $1 \mathrm{~m}$ freeboard, as with the old river meander open and by making use of the $1 \mathrm{~m}$ freeboard the whole system can still cater for discharge of $2170 \mathrm{~m}^{3} / \mathrm{s}$ multiplied by Climate Change Factor of 1.58. From the calculations at design flow, about $15 \%$ of the flow is through the old river meanders and about $85 \%$ through the bypasses. The channel side slopes of 1 in 5 with $6 \mathrm{~m}$ wide berms at $6 \mathrm{~m}$ vertical intervals, are dictated by geotechnics. Manning's Formula with coefficient of 0.035 is used to compute channel discharge capacity. 


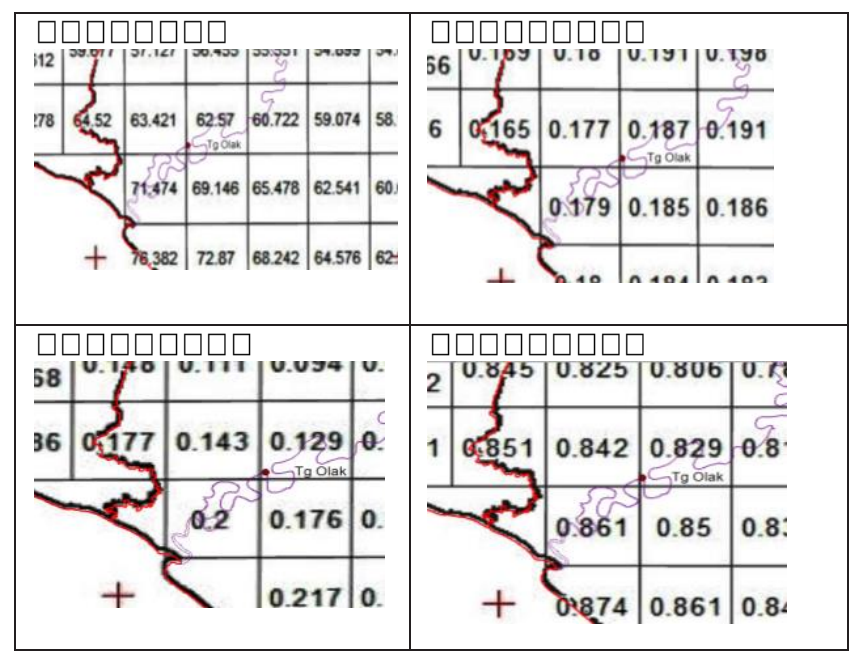

Fig. 4. The derived parameters from for Tg Olak site.

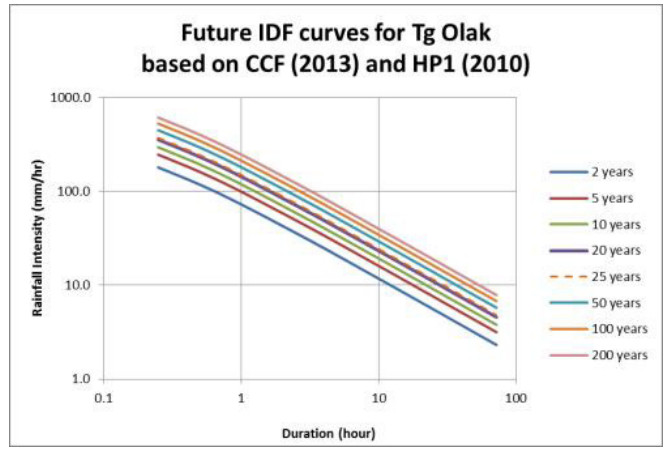

Fig. 5. The IDF curves for Tg Olak based on HP1 [7] and CCF [9].

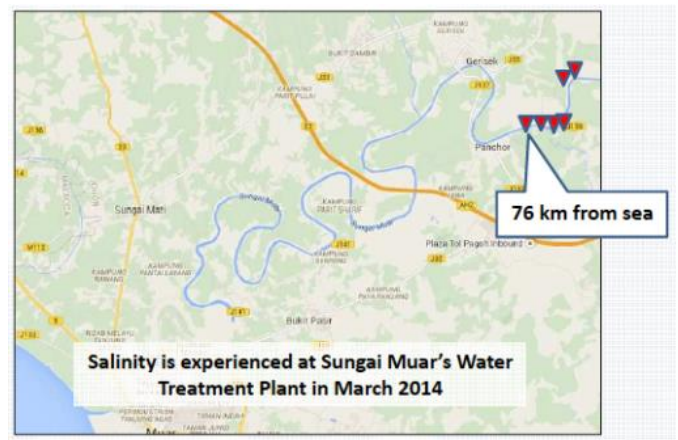

Fig. 6. Salt water in Sg Muar. 


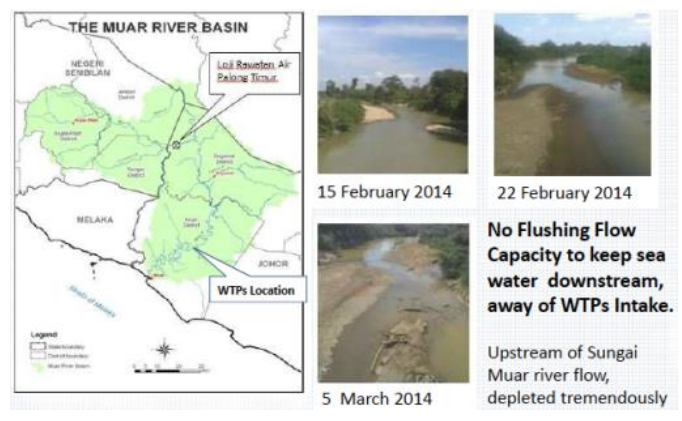

Fig. 7. Incidents on salt water intrusion.

The channel base width has been reduced from $50 \mathrm{~m}$ to $30 \mathrm{~m}$, side slopes from 1 in 6 to 1 in 5 and this has resulted in substantial earth excavation and cost savings. Fom European experience that straightening rivers by removing meanders in flood mitigation works can have negative impacts on riparian flora and fauna and river life [11], it is a wise to keep the old river meanders at both bypasses open to river flow. This not only enables barges and other bigger boats to use Sg. Muar for navigation on a status quo basis, but will also reduce any negative environmental impacts. The hydraulic calculations to determine the division of flow at the bifurcation where the river divides into the new bypass and the old meander is based on the method [12]. From the calculations it can be seen that at design flow, about $15 \%$ of the flow is through the old river meanders and about $85 \%$ through the bypasses.

\subsection{Success Criteria}

The criteria that considered in the evaluation of flood mitigation in the Muar basin are the Peak Water Level and Extent of Inundation. These criteria can be measured by significant consequence to the householder and flood mitigation works. For example for a property with a floor level of $3.5 \mathrm{~m}$, if the peak flood level exceeds $3.5 \mathrm{~m}$, then it is of significant consequence to the householder. If then, mitigation can reduce the likelihood in any given year of such a flood height being achieved from the 50 year to the 100 year flood level, then this is of consequence. Whereas flood mitigation works which reduce the extent of inundation for a given event are generally considered ideal, if the area of inundation is reduced whilst the total flood volume is not, then it is likely that the areas that remain inundated are experiencing higher velocities, higher discharges and higher levels of hazard.

\section{Conclusions}

Sg. Muar is being extracted for water supply to the States of Johor, Malacca and Negeri Sembilan. There have been incidences of salt-water intrusion into the raw water intakes, especially during the low flow event. Meanwhile, construction of the Kg. Belemang and Tg. Olak Bypasses, while speeding up flood discharges, may also increase salt-water intrusion during low flows. However, there are plans and studies being carried out now to address this problem like the construction of weir or barrage to resolve this problem. By constructing the barrage at the study area, the saltwater intrusion can be controlled. But a detailed study should be conducted in near future in order to obtain more precise information on other potential environmental and ecological effects to the area.

The authors acknowledges support from the Ministry of Higher Education Malaysia through a Fundamental Research Grant Scheme (FRGS) (Grant 600-RMI/ST/FRGS 5/3/(18/2015). The authors also would like to thank FKA UiTM, IRMI UiTM and JPS for their support to this project. 


\section{References}

1. HSS Integrated (HSSI), Cadangan Kerja-kerja Tebatan Banjir Pintasan Tanjung Olak dan Belemang di Hilir Sungai Muar (2011)

2. Research Division Malaysian Meteorological Dept, Ministry Of Science, Technology And Innovation, Report on Heavy Rainfall That Caused Floods in Johor, Melaka, Negeri Sembilan and Pahang During the Period 17th - 20th December 2006 (2006)

3. Iktisas Sdn Bhd. Sg Muar - Flood Mitigation Masterplan (2003)

4. HSS Integrated (HSSI), Hydrology Report (2009)

5. Shafie, Extreme Flood Event: A case study on Floods of 2006 and 2007 in Johor, Malaysia (2009)

6. Jabatan Pengairan dan Saliran Malaysia (JPS), HP4 - Magnitude and Frequency of Floods in Peninsular Malaysia (Revised and Updated) (1987)

7. HP1 -National Hydraulic Research Institute of Malaysia (NAHRIM), Reviewed and Updated the Hydrological Procedure No.1 (Estimation of Design Rainstorm in Peninsular Malaysia) (2010)

8. Town and Country Planning Department, Draf Rancangan Tempatan Daerah Muar 2002-2015 (Pengubahan) (2010)

9. National Hydraulic Research Institute of Malaysia (NAHRIM), Estimation of Future Design Rainstorm under the Climate Change Scenario in Peninsular Malaysia, Nahrim Technical Guide No.1 (2013)

10. A. Khomine, S. János and K. Balázs, Adv. in the Res. of Aquatic Env., 251-257 (2011)

11. V. T. Chow, Open-Channel Hydraulics. McGraw-Hill Book Company ((1973)

12. Y. L. Wan, National Seminar on Socio-Economic Impacts of Extreme Weather and Climate Changes (2007) 